\title{
Potential effect of epigenetic drugs in the treatment of multiple-site extramedullary plasmacytoma involving the respiratory system: a case report and review of the literature
}

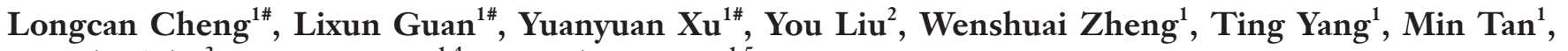 \\ Dongkai Zhu ${ }^{3}$, Xiaoning Gao ${ }^{1,4}$, Quanshun Wang ${ }^{1,5}$ \\ ${ }^{1}$ Department of Hematology, Hainan Hospital of Chinese PLA General Hospital, Sanya, China; ${ }^{2}$ Pathology department, Hainan Hospital of \\ Chinese PLA General Hospital, Sanya, China; ${ }^{3}$ Nuclear Medicine Department, Hainan Hospital of Chinese PLA General Hospital, Sanya, China; \\ ${ }^{4}$ Department of Hematology, 5th Medical Center of Chinese PLA General Hospital, Beijing, China; ${ }^{5}$ Department of Hematology, 1th Medical \\ Center of Chinese PLA General Hospital, Beijing, China \\ "These authors contributed equally to this work. \\ Correspondence to: Xiaoning Gao, Quanshun Wang. Department of Hematology, Hainan Hospital of Chinese PLA General Hospital, Sanya, China. \\ Email: gaoxn@263.net; wqs63@sohu.com.
}

\begin{abstract}
We report the case of a 23-year-old man with a medical history of idiopathic thrombocytopenic purpura (ITP) and newly diagnosed with the Epstein-Barr virus (EBV)-positive multiple-site extramedullary plasmacytoma (EMP), which involves the respiratory system. The patient was referred to our hospital because of progressive nasal congestion and nasal mass. Nasopharyngoscopy and bronchoscopy were performed. The biopsy pathological hematoxylin and eosin (HE) staining indicated plasma cell myeloma, and further immunohistochemistry CD99(+), CD79a(+), CD38(+), MUM-1(+), and Lambda(+) confirmed the diagnosis. The patient's bone marrow was normal, and hypercalcemia, renal insufficiency, anemia, evident bone lesions were not observed. Serum immunoglobulin quantification, serum protein electrophoresis, and blood and urine light chain quantification were all within the normal range. The serum immunofixation electrophoresis was negative, and the serum-free light chain was normal. These results could rule out multiple myeloma (MM) and prove to be EMP involving the nasal cavity, main bronchus, lung, and left hip. No desired effect was achieved after receiving PAD (bortezomib, adriamycin, and dexamethasone) and VRD (bortezomib, lenalidomide, and dexamethasone) treatments. Even if the tumor was remarkably relieved after receiving the 2-course CHOP (cyclophosphamide, doxorubicin, vincristine, and prednisone) regimen, secondary resistance to $\mathrm{CHOP}$ unfortunately occurred in this case. We attempted to apply epigenetic therapy in the treatment of refractory multiple EMP. Although no complete remission (CR) was achieved, the maximum standard uptake value (SUVmax) in tumor lesions was significantly lower than before, and the patient's symptoms significantly improved. The patient tolerated decitabine and chidamide. We speculated that epigenetic drugs have potential effect in the treatment of multiple-site EMP.
\end{abstract}

Keywords: Extramedullary plasmacytoma (EMP); Epstein-Barr virus; respiratory system; epigenetic therapy; case report

Submitted Jan 11, 2021. Accepted for publication Jun 21, 2021.

doi: $10.21037 /$ tcr-21-68

View this article at: https://dx.doi.org/10.21037/tcr-21-68

\section{Introduction}

Plasmacytoma is a neoplasm that encompasses a group of the monoclonal proliferation of plasma cells deriving from mature, terminally differentiated B cells. The EMP is an uncommon type of mature B-cell neoplasms and accounts for only $3-5 \%$ of all plasma cell neoplasms (1-3). The disease may occur in various soft tissues throughout 

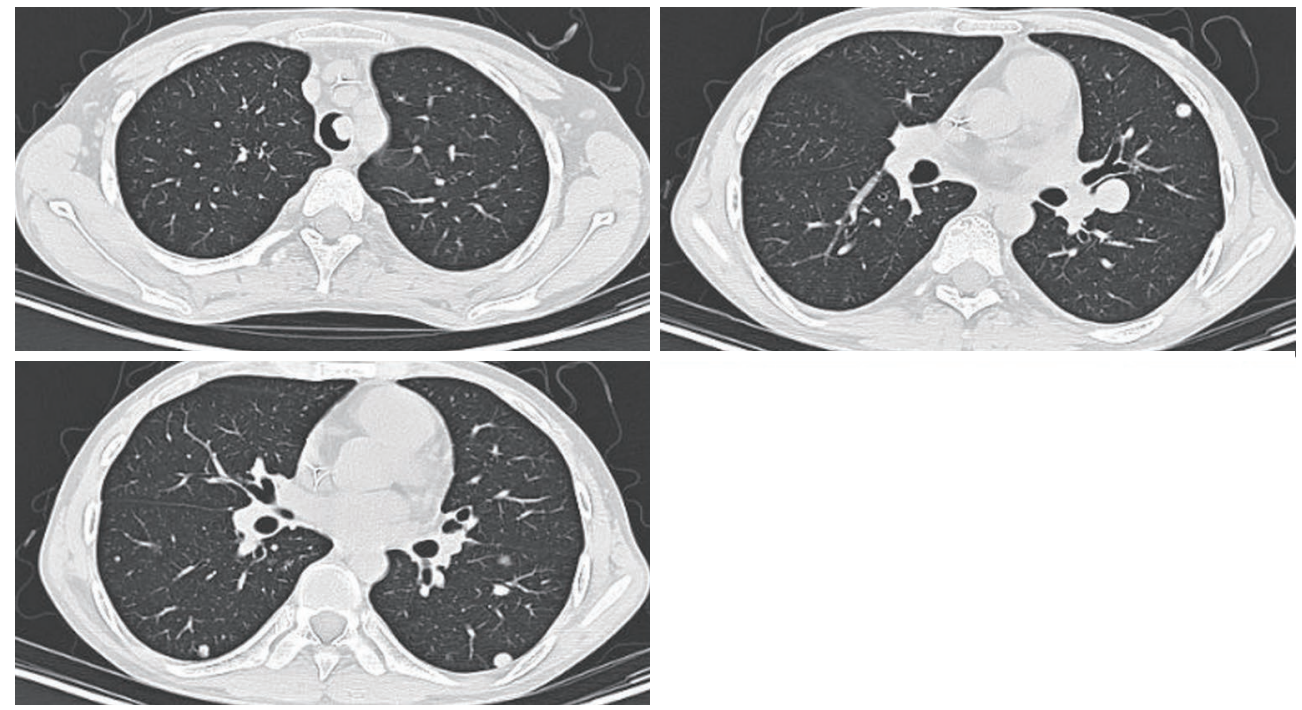

Figure $1 \mathrm{CT}$ scan showing the main bronchus mass and multiple nodules in the lungs.

the body, but most of these tumors arise in the upper respiratory tract especially in the nasal cavity and paranasal sinuses $(4,5)$. Numerous studies reported that the EBV infection is related to the occurrence of various lymphoid proliferations, such as Burkitt lymphoma, extranodal NK/ T-cell lymphoma, and nasal-type and immunodeficiencyassociated lymphoproliferative disorders (6). Whether EBV(+) plasmacytomas are prone to secondary to immunosuppressive or immunocompetent conditions remains unknown. We report a case of $\mathrm{EBV}(+) \mathrm{EMP}$ synchronously involving nasal cavity, trachea, lung, and left hip, which is infrequent. We present the following article in accordance with the CARE reporting checklist (available at https://dx.doi.org/10.21037/tcr-21-68).

\section{Case presentation}

A 23-year-old male with a medical history of ITP and nodal tachycardia was referred to our hospital due to progressive nasal congestion and nasal mass. The patient was diagnosed with ITP at the age of 2 years. He was treated with hormones (steroids), rituximab, gamma globulin, and thrombopoietin, and the disease relapsed repeatedly. A series of laboratory tests was performed at admission. The platelet counts, hemoglobin count, serum albumin level, serum lactate dehydrogenase level, serum $\beta_{2}$ - macroglobulin level, serum creatinine level, and EBV DNA replication level were $47 \times 10^{9}\left(100-300 \times 10^{9}\right)$ per L, 118 [137-179] g/L, 41.6 [35-50] g/L, 223 [40-250] U/L, $0.206(0.07-0.18) \mathrm{mg} / \mathrm{dL}$,
$48[30-110] \mu \mathrm{mol} / \mathrm{L}$, and 15,000 copies/L (normal reference value $<1,000$ copies/L), respectively. The values of various serum immunoglobulins were as follows: IgG, 771 [700-1,600] mg/dL; IgM, 53.1 [40-230] mg/dL; IgA, $48[70-400] \mathrm{mg} / \mathrm{dL}$; and IgE, 243 [0-100] IU/mL. Blood and urine immunofixation electrophoreses were negative, and the serum-free light chain was normal. Two bone marrow aspirations and biopsies did not show any plasma cell. The flow cytometry of cells prepared from the biopsy specimens had never shown CD38(+) and CD138(+) plasma cells. No karyotypic abnormality was found by conventional chromosome analysis of the cells. Physical examination revealed a diffuse maculopapular rash on the trunk and extremities with itching. The CT scan of the patient's lung showed the main bronchus mass and multiple nodules in the lungs (Figure 1). The nasal pharyngeal enhanced MRI suggested irregular thickening of the posterior wall of the nasopharynx, abnormal signs of the left arytenoid epiglottis, and right nasal mass, thereby showing the possibility of neoplastic lesions (Figure 2). Nasopharyngoscopy and bronchoscopy were performed. The histopathological examination of the nasal cavity and main bronchial mass biopsy specimens showed that cytoplasmic red-stained tumor cells were diffusely distributed, and tumor cells had uniform size and nuclear deviation. Upon immunohistochemical staining, tumor cells were phenotypically characterized by CD20(-), CD56(-), CD3(-), CD10(-), bcl-6(-), CD99(+), CD79a(+), CD38(+), CD138(-), CD5(-), MUM-1(+), Kappa(-), Lambda(+), and ki-67(20\%+). The fluorescence 

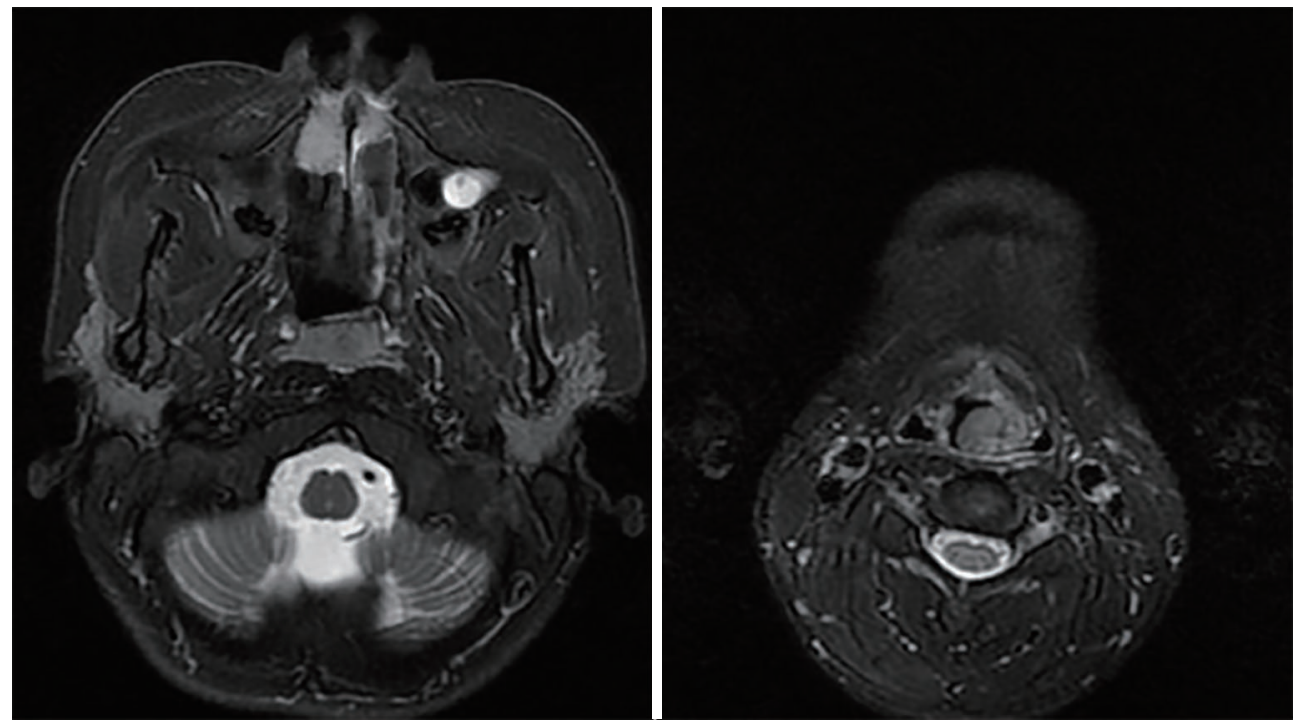

Figure 2 Nasal pharyngeal enhanced MRI showing irregular thickening of the posterior wall of the nasopharynx, abnormal signs of the left arytenoid epiglottis, and right nasal mass.

in situ hybridization suggested EBV-EBER(+) (Figure 3). Based on the diagnosis of multiple EMP, the patient received 3 courses of PAD treatment (Bortezomib, $1.3 \mathrm{mg} / \mathrm{m}^{2}$ 1/day d1, d4, d8, and d11; Adriamycin, $15 \mathrm{mg} / \mathrm{m}^{2} 1 /$ day d1; and Dexamethasone, $20 \mathrm{mg}$ 1/day d1-2, d4-5, d8-9, and d11-12) from March 2018 to May 2018, 2 courses of VRD treatment (Bortezomib, $1.3 \mathrm{mg} / \mathrm{m}^{2}$ 1/day d1, d4, d8, and d11; Lenalidomide, $25 \mathrm{mg}$ 1/day d1, d3, d5, d7, d9, d11, and d13; and Dexamethasone, $20 \mathrm{mg} \mathrm{1/day} \mathrm{d} 1-2, \mathrm{~d} 4-5, \mathrm{~d} 8-9$, and d11-12) from June 2018 to July 2018, 4 courses of reduceddose CHOP treatment (Cyclophosphamide, $450 \mathrm{mg} / \mathrm{m}^{2}$ 1/day d1; Doxorubicin, $15 \mathrm{mg} / \mathrm{m}^{2} 1 /$ day d1; Vincristine, $4 \mathrm{mg} \mathrm{1/day} \mathrm{d1;} \mathrm{and} \mathrm{Prednisone,} 60 \mathrm{mg} \mathrm{1/day} \mathrm{d1-5)} \mathrm{from}$ September 2018 to December 2018 in succession. After the 3-course PAD therapy, MRI revealed the progression of the right nasal mass (Figure 4). The lesions involved in the respiratory system did not shrink and reduce after two courses of VRD regimen. Thus, we chose the reduced-dose $\mathrm{CHOP}$ regimen in the sixth course of treatment. Through the 2-course CHOP chemotherapy, 18F-fluorodeoxyglucosepositron emission tomography/computed tomography (FDG-PET/CT) revealed that the nodules in the right lower nasal passage, posterior nasopharyngeal wall, left arytenoid epiglottis, left hip, and the main bronchus were smaller than the previous, that the metabolism of these nodules were significantly reduced, and that the nodule in the right lung tip and the subpleural nodule in the right lower lobe clearly disappeared (Figure 5). However, the disease was evaluated as progressive disease after the 4-course $\mathrm{CHOP}$ treatment, and the FDG-PET/CT showed that the intranasal nodule metabolism was significantly higher than before (Figure 6). The EBV DNA replication level increased to 31400 copies/L. We performed a nasopharyngeal tumor biopsy again, and pathological results still suggested EMP (Figure 7). From January 2019 to March 2019, the 3-course chemotherapy with decitabine and chidamide (Decitabine, $10 \mathrm{mg} / \mathrm{m}^{2} 1 /$ day d $1-5$ and Chidamide, $30 \mathrm{mg}$ 1/day d 1 and d5) were given since the disease progressed. The patient's nasal congestion improved. PET/CT revealed that the left arytenoid epiglottis, posterior nasopharyngeal wall, and right lower nasal passage soft tissue metabolism decreased (Figure 8). The EBV DNA replication level decreased to 1,060 copies/L. Eosinophil counts abnormally increased several times during the treatment, but no evidence of parasitic infection and allergic disease was found. We considered this phenomenon to be related to tumors, but no correlation with the treatment effect was found. Subsequently, the patient continued to receive six courses of decitabine plus chidamide until the chest CT revealed disease progression in September 2019. Since then, the patient quit therapy due to personal family conditions. All procedures performed in studies involving human participants were in accordance with the ethical standards of the institutional and/or national research committee(s) and the Helsinki 

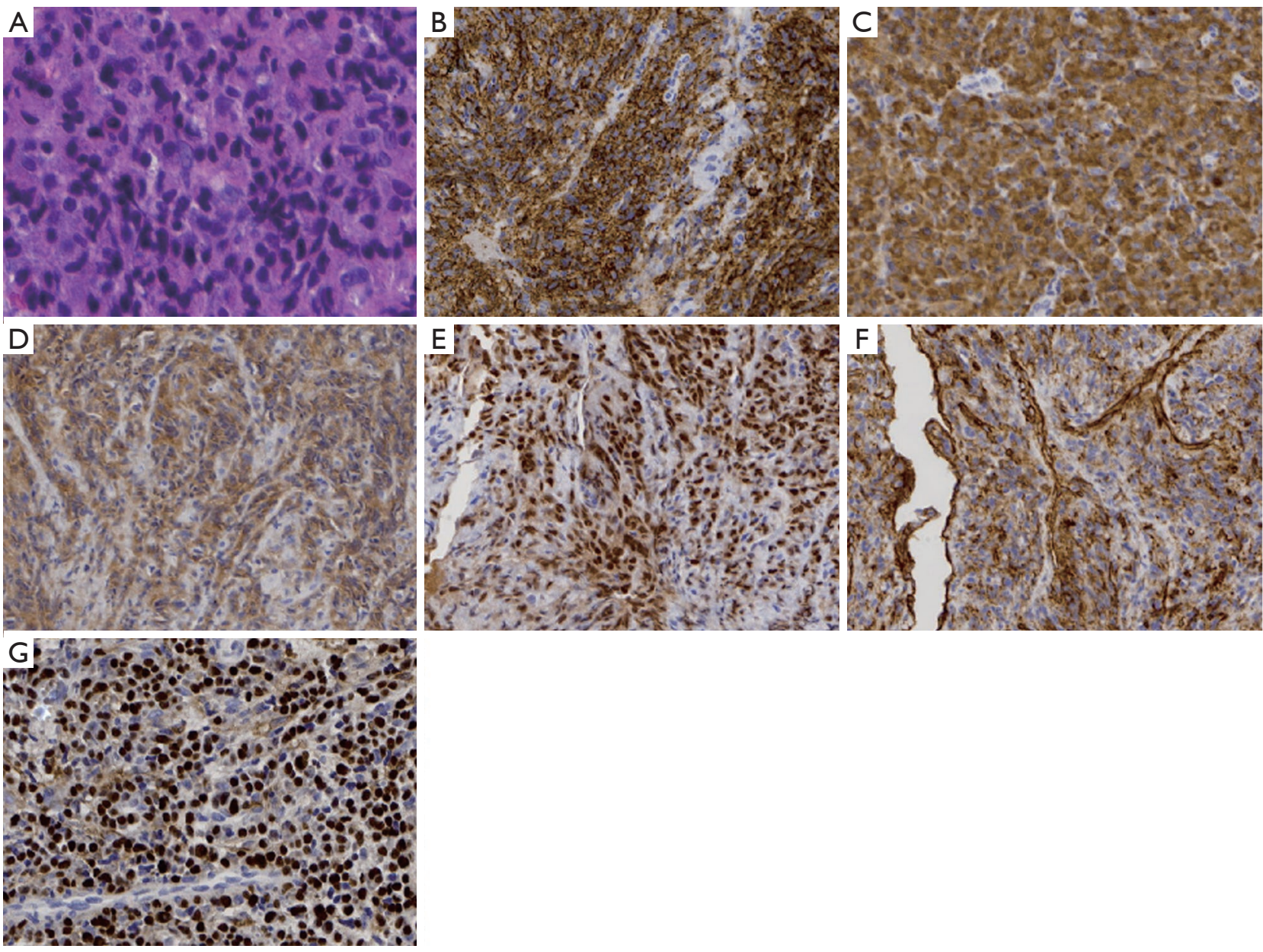

Figure 3 Pathological examination confirming extramedullary plasmacytoma. (A) HE staining (main bronchus nodule) showing that the cytoplasmic red-stained tumor cells were diffusely distributed and that the tumor cells had uniform size and nuclear deviation. (B) Positive CD38. (C) Positive CD79a. (D) Positive Lambda. (E) Positive MUM-1. (F) Positive CD99. (G) In situ hybridization for Epstein-Barr virusencoded RNA (EBER) showed positive reaction in tumor cells. Magnification: 20×. HE, hematoxylin and eosin.

Declaration (as revised in 2013). Written informed consent was obtained from the patient.

\section{Discussion}

The EMP, a plasma cell tumor originating from soft tissues, usually occurs as a solitary tumor in the head and neck, such as the pharynx, paranasal sinuses, nasal cavity, or oral cavity (7-9), and accounts for $80 \%$ of cases. The primary plasmacytoma of the lung is a relatively rare tumor. Gordon and Walker reported the first case in 1944 (10). The usual presentation of the primary pulmonary plasmacytoma is a solitary pulmonary nodule but sometimes mimics an inflammatory infiltrate or presents as multiple nodules.
The diffuse primary plasmacytoma of the nasal cavity, main bronchus, and lung is particularly rare, and no report is available. The diagnosis of EMP depends on pathological biopsy and immunohistochemistry, and laboratory and imaging examinations are necessary. The diagnostic criteria of EMP include the following: (I) pathologically confirmed plasmacytoma originating outside the bone marrow, (II) healthy bone marrow, (III) no MM-related clinical manifestation and related laboratory test positive indicator, (IV) no monoclonal immunoglobulin or a small amount of monoclonal immunoglobulin detected (11). EMP is rarely positive for EBV-encoded RNA 1 (EBER1). EBV latently infecting memory B cells initiates EBV replication and lytic cycle in vivo during the terminal differentiation into plasma 

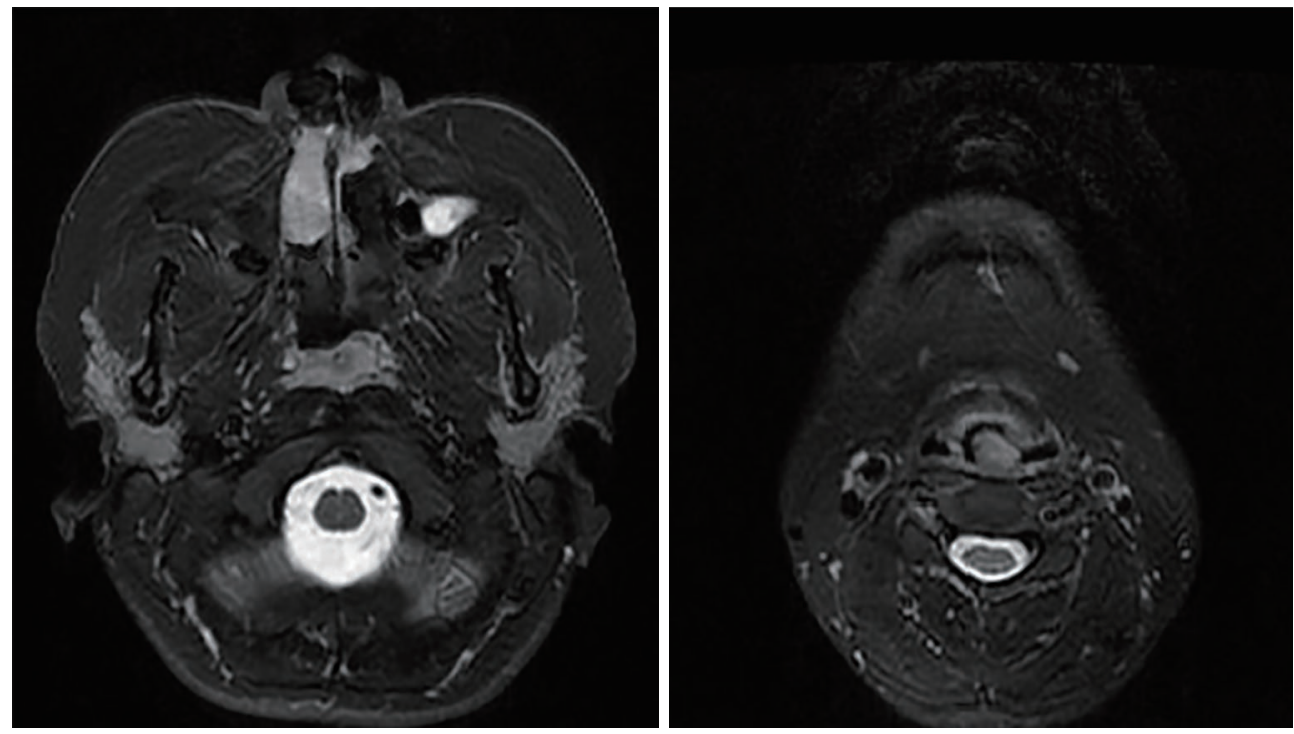

Figure 4 MRI revealing the progression of the right nasal mass after the 3-course PAD therapy. PAD, bortezomib, adriamycin, and dexamethasone.

cells (12). Two studies reported six cases of EBER1(+) EMP in immunocompetent patients $(13,14)$.

The EMP is present in less than $5 \%$ of all plasma cell neoplasms, and the 15 -year survival rate is $78 \%$ in a retrospective study (15). We summarized seven patients with EMP involving the respiratory system, including 2 males and 5 females with a median age of 65 [26-83] years (10,16-21) (Table 1). A 26-year-old patient had previously received immunosuppressive therapy (17), which is the same as the one we reported. The incidence of young patients with extramedullary plasmacytoma (EMP) is speculated to be associated with long-term immune disorders. Monoclonal gammopathy ( $\mathrm{M}$ component) can be detected in $25 \%$ of patients with EMP (19). Although the presence of monoclonal gammopathy in the serum or urine does not exclude a diagnosis of EMP, the presence of plasma serum $M$ protein at diagnosis may suggest a prognostic factor for disseminated disease (22). Of the seven patients, five $(71.4 \%)$ with multiple EMP in the respiratory system had shown $M$ components in the peripheral blood. At present, EMP treatments include radiotherapy, surgery, and chemotherapy (23). Given that the EMP has high sensitivity to radiotherapy, which has a high rate of control, most scholars recommend this means as the primary alternative $(24,25)$. Radiotherapy should be performed on the primary tumor and nearby lymph nodes, and the total amount is 40-50 Gy. Patients with limited lesions and complete resection choose surgery alone, whereas patients who cannot be wholly resected can be treated with radiotherapy after resection. For patients with disease progression or poor prognostic factors (such as poor differentiation, local destruction, and prominent infiltration), the commonly used regimen is MP (melphalan and prednisone) or CHOP. The chemotherapy regimen for myeloma is the main treatment for multiple EMP. Several reports showed that bortezomibbased chemotherapy has a good therapeutic effect on EMP and that some patients can even achieve CR (26-28). Six of 7 patients with multiple EMP we reviewed received MP therapy or regimens based on MP. After 4-16 courses of chemotherapy, 5/6 patients were effectively controlled, symptoms improved significantly, and three patients even achieved CR. Only one patient died of multiple organ failure secondary to tumor lysis syndrome and side effects of the drug. In this case, the patient showed primary and secondary resistance to the traditional treatment regimen. After nine courses of treatment, nasal congestion symptoms did not improve significantly, and the patient never achieved remission.

During the treatment, the patient developed complications, such as acute gastroenteritis, pulmonary infection, and peripheral neuritis, and anxiety and depression appeared. The patient we reported received a 5-course bortezomibbased chemotherapy regimen and did not achieve remission. Thus, the use of bortezomib in multiple EMP involving the 

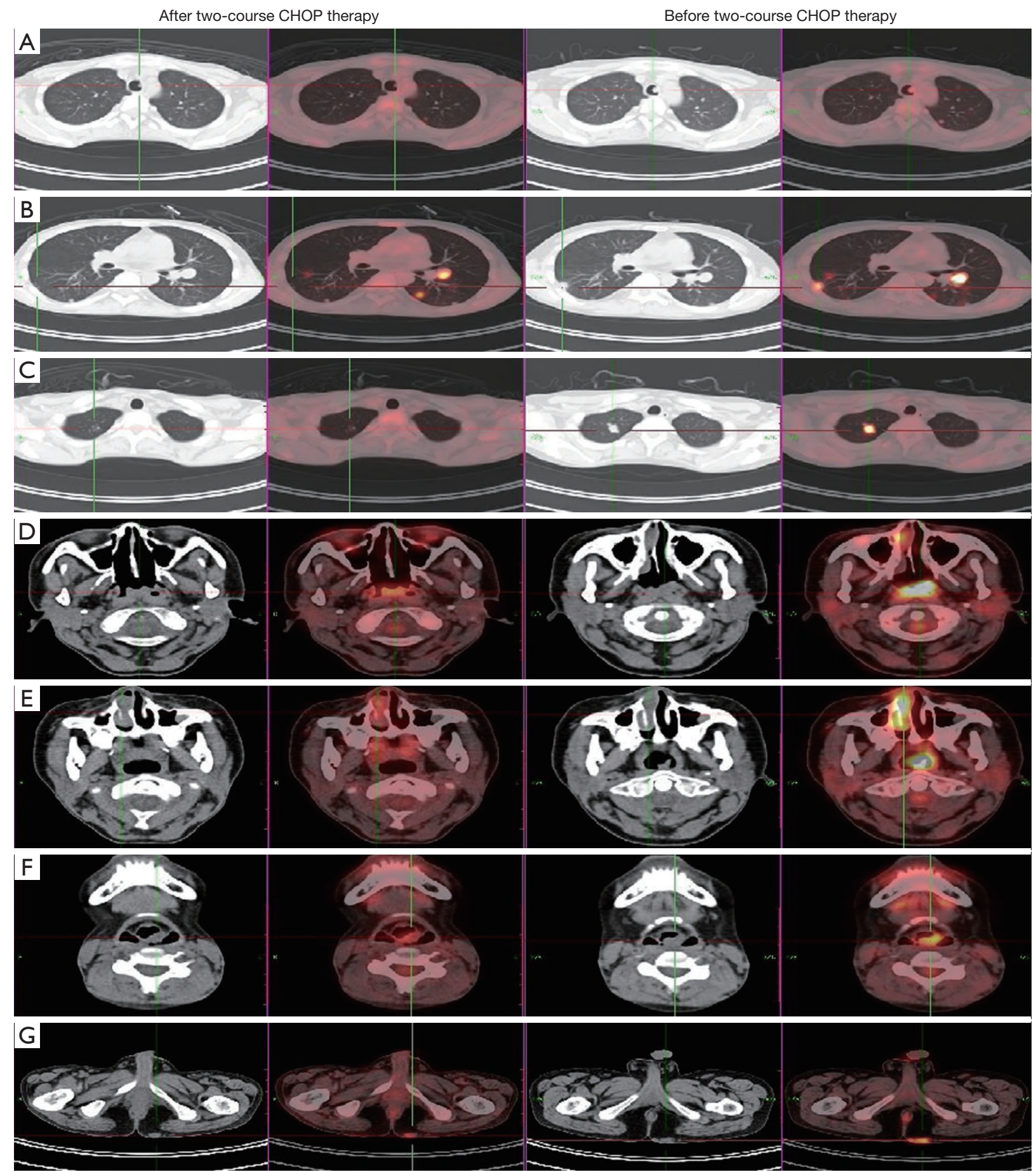

Figure 5 FDG-PET/CT revealing that the (C) nodule in the right lung tip and the (B) subpleural nodules in the right lower lobe clearly disappeared. (A) Decreased degree of the radioactive uptake of the main bronchus nodule than before (SUVmax, 0.8 vs. 1.9). (D) Decreased degree of the radioactive uptake of the posterior nasopharyngeal wall nodule than before (SUVmax, 3.6 vs. 11.4). (E) Decreased degree of the radioactive uptake of the right lower nasal passage nodule than before (SUVmax, 3.2 vs. 7.8). (F) Decreased degree of the radioactive uptake of the left arytenoid epiglottis nodule than before (SUVmax, 2.5 vs. 5.9). (G) Decreased degree of the radioactive uptake of the left hip nodule than before (SUVmax, 2.1 vs. 4.8). These nodules were also smaller than the previous. FDG-PET/CT, 18F-fluorodeoxyglucosepositron emission tomography/computed tomography; SUVmax, maximum standard uptake value. 

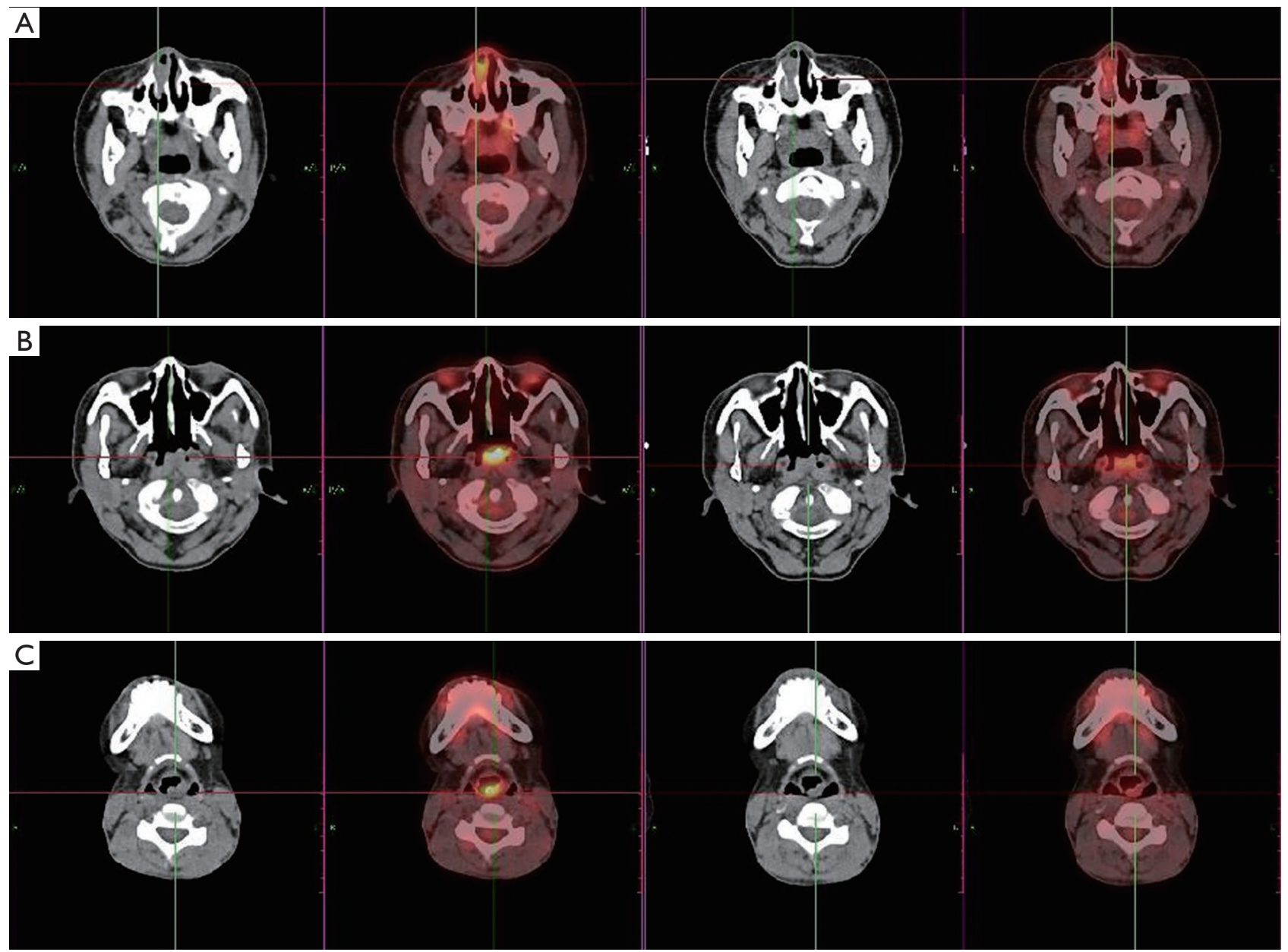

Figure 6 FDG-PET/CT showing (A) significantly higher right lower nasal passage nodule metabolism than before (SUVmax, 4.4 vs. 3.2), (B) significantly higher posterior nasopharyngeal wall nodule metabolism than before (SUVmax, 8.1 vs. 3.6), and (C) significantly higher left arytenoid epiglottis nodule metabolism than before (SUVmax, 8.0 vs. 2.5). FDG-PET/CT, 18F-fluorodeoxyglucose-positron emission tomography/computed tomography; SUVmax, maximum standard uptake value.

respiratory system still needs research. Some studies showed that epigenetic changes are deeply involved in the occurrence and development of plasma cell myeloma $(29,30)$. Several studies demonstrated that histone deacetylase (HDAC) inhibitors (such as chidamide) can induce DNA damage and apoptotic cell death in MM (31-33). A combination of a DNA methyltransferase inhibitor and a HDAC inhibitor is reported to increase the immunogenicity of myeloma cells and alter the immune cell constitution in the bone marrow of myeloma-bearing mice (34). Therefore, to control the patient's respiratory diseases, we gave patients a 3 -course epigenetic therapy composed of decitabine plus chidamide. The patient showed a significant improvement in nasal congestion symptoms after the second course of treatment. The SUVmax of tumor is significantly lower than before, and the patient did not experience severe side effects during treatment and tolerated epigenetic therapy well. The patient achieved disease progression-free survival for up to eight months, which was much longer than the treatments of $\mathrm{PAD}, \mathrm{VRD}$, and $\mathrm{CHOP}$.

We presented a rare case of EMP simultaneously involving the nasopharynx, larynx, trachea, lungs, and left hip. When lesions are disseminated, which is not appropriate for radiotherapy and operation, we put chemotherapy as the preferred treatment. The disease was not effectively relieved after receiving PAD and VRD treatments and still needed research to testify the efficacy of the new drug, such 

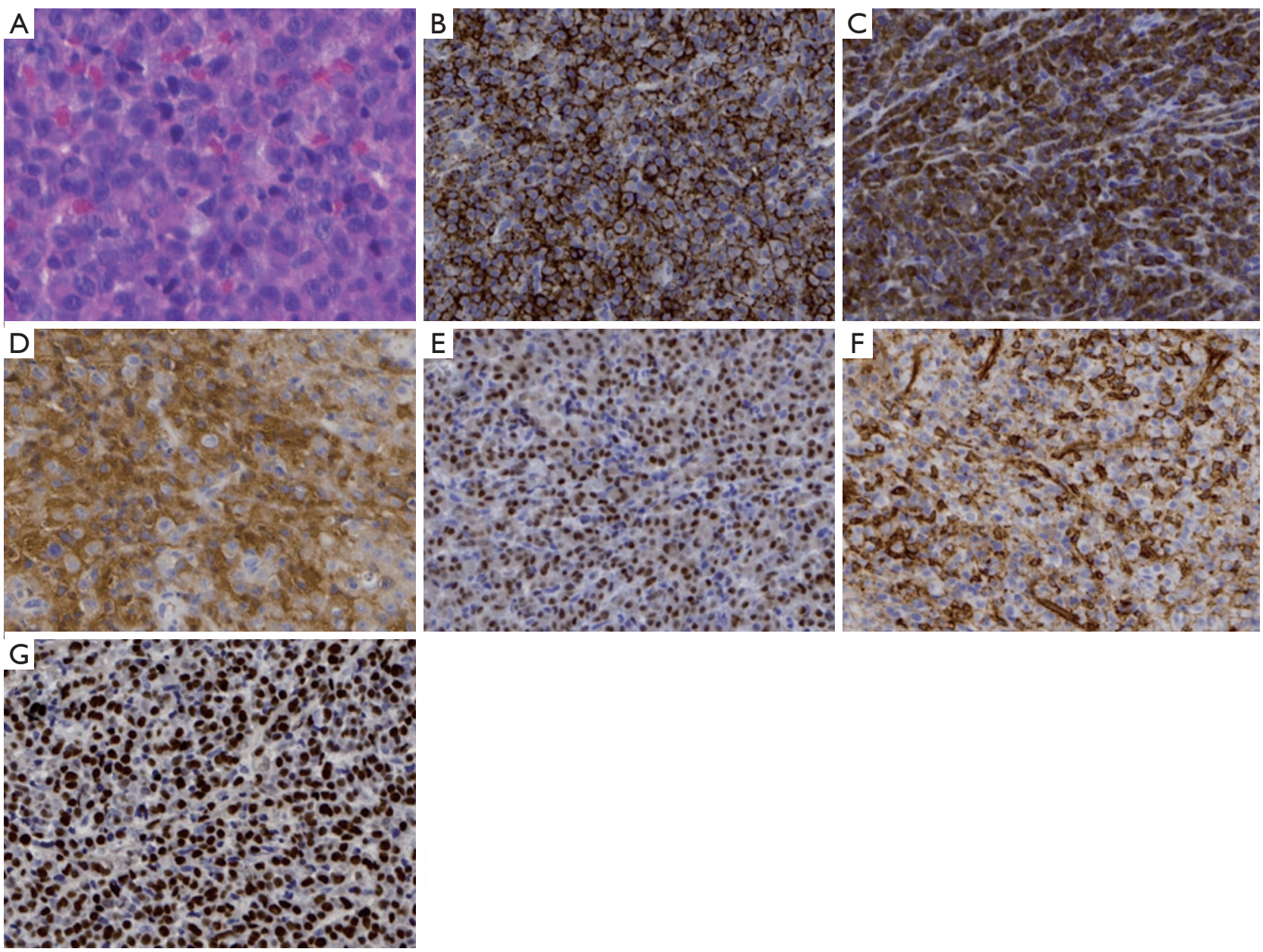

Figure 7 Pathological examination reconfirming extramedullary plasmacytoma. (A) HE staining (nasal cavity nodule) showing the redstained cytoplasm of tumor cells. (B) Positive CD38. (C) Positive CD79a. (D) Positive Lambda. (E) Positive MUM-1. (F) Positive CD99. (G) In situ hybridization for Epstein-Barr virus-encoded RNA (EBER) showed positive reaction in tumor cells. Magnification: 20x. HE, hematoxylin and eosin.

as bortezomib and lenalidomide, in multiple EMP. Even if the tumor was significantly relieved after receiving the 2-course CHOP regimen, secondary resistance to $\mathrm{CHOP}$ unfortunately occurred in this case. We attempted to apply epigenetic therapy in the treatment of multiple refractory EMP. Although no complete remission (CR) was achieved, the patient's symptoms were significantly improved, and the patient tolerated decitabine and chidamide well. Whether 
After three-course therapy with decitabine and chidamide
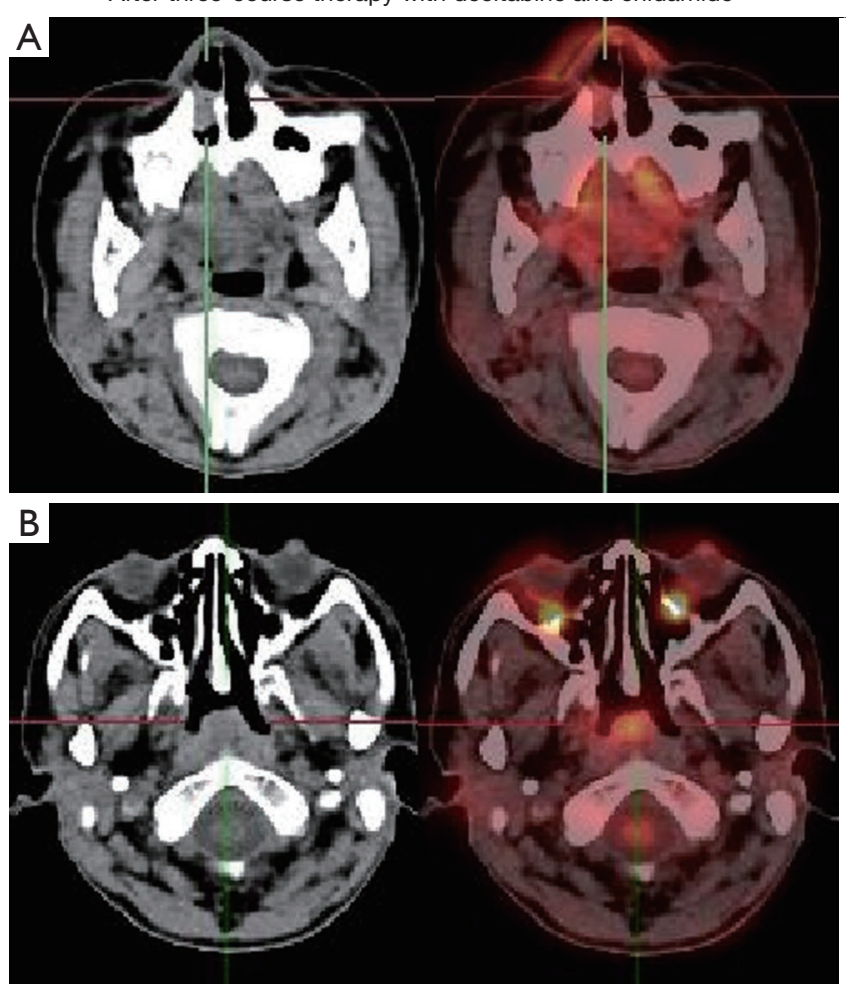

C

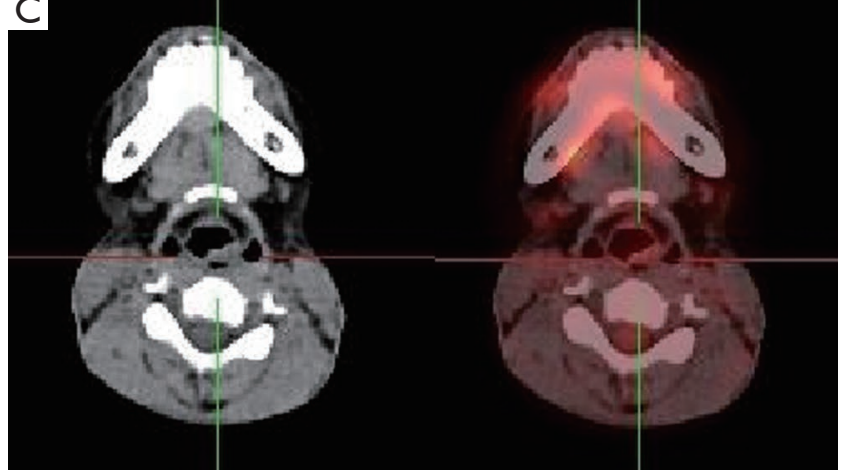

Before three-course therapy with decitabine and chidamide
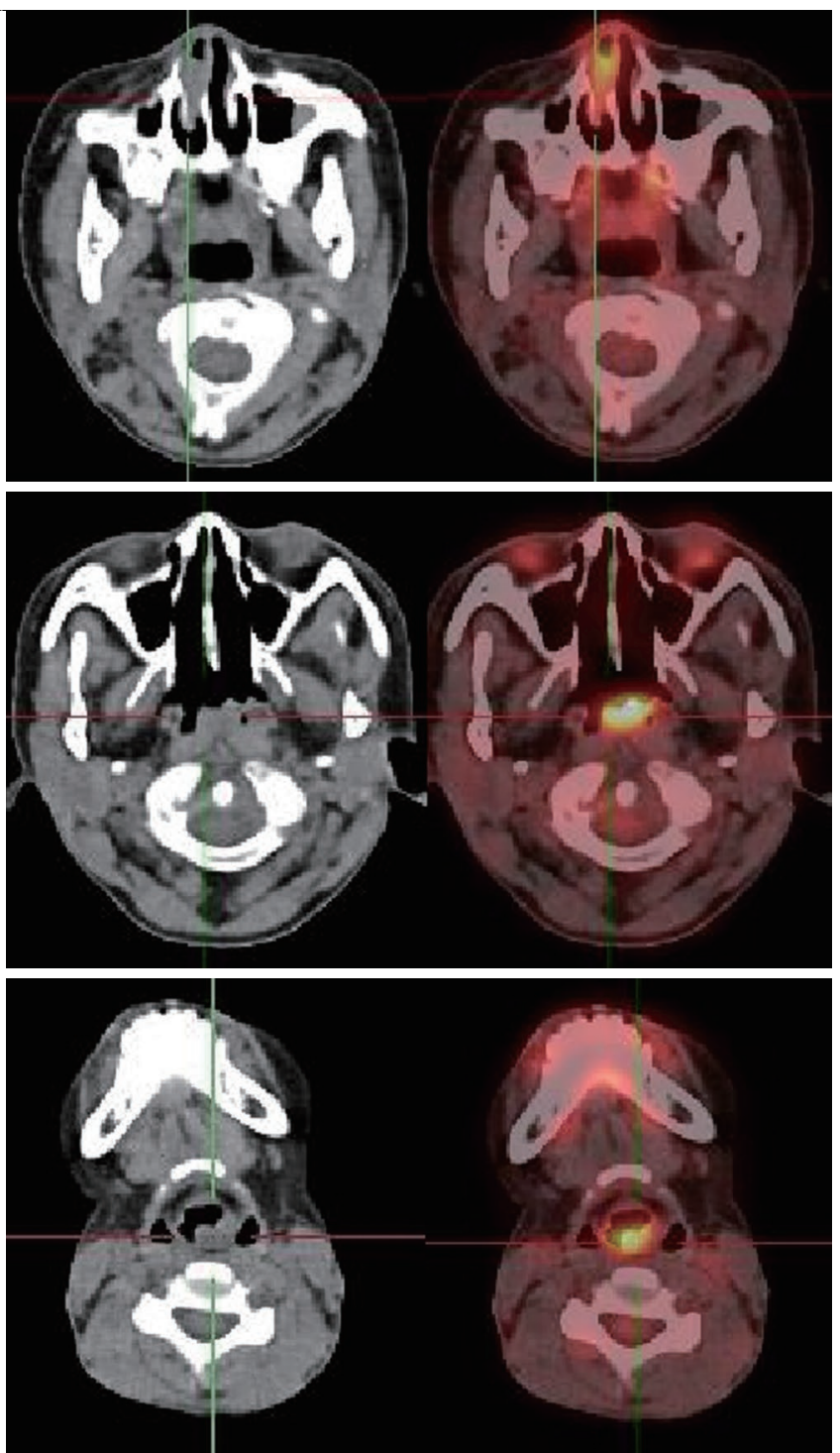

Figure 8 Pathological examination reconfirming extramedullary plasmacytoma. (A) HE staining (nasal cavity nodule) showing the redstained cytoplasm of tumor cells. (B) Positive CD38. (C) Positive CD79a. (D) Positive Lambda. (E) Positive MUM-1. (F) Positive CD99. (G) In situ hybridization for Epstein-Barr virus-encoded RNA (EBER) showed positive reaction in tumor cells. Magnification: 20x. HE, hematoxylin and eosin. 
Table 1 Clinical characteristics and outcome of patients with extramedullary plasmacytoma involving the respiratory system

\begin{tabular}{|c|c|c|c|c|c|c|c|}
\hline Author, year & Age & Gender & Symptoms & Signs & $\begin{array}{c}\text { M } \\
\text { components } \\
\text { in PB }\end{array}$ & Treatment & Outcome \\
\hline $\begin{array}{l}\text { Sang-Heon, } \\
2012\end{array}$ & 26 & Women & $\begin{array}{l}\text { Slight sputum without } \\
\text { other respiratory } \\
\text { symptoms such as } \\
\text { dyspnea or chest pain }\end{array}$ & $\begin{array}{l}\text { Infiltrative lesions in both } \\
\text { lower lung fields }\end{array}$ & None & $\begin{array}{l}6 \text { cycles } \\
\text { of the MP } \\
\text { therapy }\end{array}$ & $\begin{array}{l}\text { Near complete radiological } \\
\text { resolution was observed after } \\
\text { six cycles of treatment }\end{array}$ \\
\hline $\begin{array}{l}\mathrm{Ge}, \\
2015\end{array}$ & 83 & Man & $\begin{array}{l}\text { Cough with yellow } \\
\text { sputum and hemoptysis }\end{array}$ & $\begin{array}{l}\text { A mass in the upper } \\
\text { lobe of the right lung, } \\
\text { large nodule in the right } \\
\text { lower lung and multiple } \\
\text { nodules in both lungs }\end{array}$ & None & Untreated & Died 10 months after diagnosis \\
\hline $\begin{array}{l}\text { Singhal, } \\
2010\end{array}$ & 77 & Women & $\begin{array}{l}\text { Intermittent episodes } \\
\text { of dyspnea with } \\
\text { associated band-like } \\
\text { pain across chest }\end{array}$ & $\begin{array}{l}\text { Right pleural-based } \\
\text { mass }(3.7 \mathrm{~cm}) \text { with } \\
\text { associated rib fracture, } \\
\text { left pleural-based mass } \\
(2.6 \mathrm{~cm}) \text { with associated } \\
\text { rib destruction, mass } \\
(10 \mathrm{~cm}) \text { with destroyed } \\
\text { thoracic vertebral body } \\
\text { in subcarinal region }\end{array}$ & $\lg G$ & $\begin{array}{l}4 \text { cycles of } \\
\text { intravenous } \\
\text { Bortezomib }\end{array}$ & $\begin{array}{l}\text { Following chest X-ray showed } \\
\text { rapidly shrinking thoracic } \\
\text { tumors over the next few days, } \\
\text { patient terminally succumbed to } \\
\text { multiple organ failure secondary } \\
\text { to tumor lysis syndrome and } \\
\text { side effects of Bortezomib }\end{array}$ \\
\hline $\begin{array}{l}\text { Mohammad, } \\
2010\end{array}$ & 60 & Women & $\begin{array}{l}\text { A history of dry cough, } \\
\text { purulent productive } \\
\text { cough, solid meal } \\
\text { dysphagia, fever, chills, } \\
\text { sweating, weight loss, } \\
\text { and loss of appetite }\end{array}$ & $\begin{array}{l}\text { Right-sided parenchymal } \\
\text { alveolar consolidation } \\
\text { and nodular infiltration } \\
\text { in the left lung, nodular } \\
\text { opacity in the right } \\
\text { middle lobe }\end{array}$ & 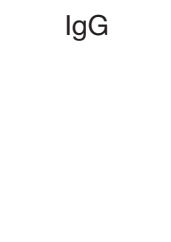 & $\begin{array}{l}4 \text { monthly } \\
\text { courses of } \\
\text { MP therapy }\end{array}$ & $\begin{array}{l}\text { The chest X-ray became normal } \\
\text { and the patient was free of } \\
\text { symptoms }\end{array}$ \\
\hline $\begin{array}{l}\text { Niitsu, } \\
2005\end{array}$ & 71 & Women & Hyperproteinemia & $\begin{array}{l}\text { A tumor in the right } \\
\text { middle lobe and another } \\
\text { tumor in the segment } 6-8 \\
\text { of the left lung }\end{array}$ & $\lg G$ & $\begin{array}{l}3 \text { courses } \\
\text { of MP } \\
\text { therapy }\end{array}$ & $\begin{array}{l}\text { The patient's serum IgG } \\
\text { level was decreased and the } \\
\text { shadows in the lungs showed } \\
\text { considerable diminution in the } \\
\text { size }\end{array}$ \\
\hline
\end{tabular}

PB, peripheral blood; MP, Melphalan and Prednisone, VMCP, Vincristine, Melphalan, cyclophosphamide, and Prednisone.

epigenetic therapy can dramatically improve the progressionfree survival and overall survival of patients with multiple EMP in the respiratory system should be studied.

\section{Acknowledgments}

The authors thank the patient for agreement to publication 
of the report. We appreciate Dr. Fu for checking the English language of the manuscript as a native speaker.

Funding: None.

\section{Footnote}

Reporting Checklist: The authors have completed the CARE reporting checklist. Available at https://dx.doi. org/10.21037/tcr-21-68

Peer Review File: Available at https://dx.doi.org/10.21037/ tcr-21-68

Conflicts of Interest: All authors have completed the ICMJE uniform disclosure form (available at https://dx.doi. org/10.21037/tcr-21-68). The authors have no conflicts of interest to declare.

Ethical Statement: The authors are accountable for all aspects of the work in ensuring that questions related to the accuracy or integrity of any part of the work are appropriately investigated and resolved. All procedures performed in studies involving human participants were in accordance with the ethical standards of the institutional and/or national research committee(s) and the Helsinki Declaration (as revised in 2013). Written informed consent was obtained from the patient for publication of this case report and accompanying images. A copy of the written consent is available for review by the editorial office of this journal.

Open Access Statement: This is an Open Access article distributed in accordance with the Creative Commons Attribution-NonCommercial-NoDerivs 4.0 International License (CC BY-NC-ND 4.0), which permits the noncommercial replication and distribution of the article with the strict proviso that no changes or edits are made and the original work is properly cited (including links to both the formal publication through the relevant DOI and the license). See: https://creativecommons.org/licenses/by-nc-nd/4.0/.

\section{References}

1. Jacob PM, Nair RA, Koshy SM, et al. Solitary plasmacytoma of the metacarpal bone in an adolescent. Indian J Pathol Microbiol 2014;57:323-5.

2. Sabattini E, Bacci F, Sagramoso C, et al. WHO classification of tumours of haematopoietic and lymphoid tissues in 2008: an overview. Pathologica 2010;102:83-7.

3. Saito M, Morioka M, Izumiyama K, et al. Epstein-Barr virus-positive ileal extraosseous plasmacytoma containing plasmablastic lymphoma components with CD20-positive lymph node involvement. Int J Gen Med 2012;5:715-8.

4. Strojan P, Soba E, Lamovec J, et al. Extramedullary plasmacytoma: clinical and histopathologic study. Int J Radiat Oncol Biol Phys 2002;53:692-701.

5. Sasaki R, Yasuda K, Abe E, et al. Multi-institutional analysis of solitary extramedullary plasmacytoma of the head and neck treated with curative radiotherapy. Int J Radiat Oncol Biol Phys 2012;82:626-34.

6. Vockerodt M, Yap LF, Shannon-Lowe C, et al. The Epstein-Barr virus and the pathogenesis of lymphoma. $\mathrm{J}$ Pathol 2015;235:312-22.

7. Bataille R. Localized Plasmacytomas. Clin Haematol 1982;11:113-22.

8. Wiltshaw E. The natural history of extramedullary plasmacytoma and its relation to solitary myeloma of bone and myelomatosis. Medicine (Baltimore) 1976;55:217-38.

9. Kapadia SB, Desai U, Cheng VS. Extramedullary plasmacytoma of the head and neck. A clinicopathologic study of 20 cases. Medicine (Baltimore) 1982;61:317-29.

10. Lazarevic V, Cemerikic-Martinovic V, Suvajdzic N, et al. Diffuse primary plasmacytoma of the lung. Haematologia (Budap) 2001;31:161-5.

11. International Myeloma Working Group. Criteria for the classification of monoclonal gammopathies, multiple myeloma and related disorders: a report of the International Myeloma Working Group. Br J Haematol 2003;121:749-57.

12. Al Tabaa Y, Tuaillon E, Bollore K, et al. Functional Epstein-Barr virus reservoir in plasma cells derived from infected peripheral blood memory B cells. Blood 2009;113:604-11.

13. Yan J, Wang J, Zhang W, et al. Solitary plasmacytoma associated with Epstein-Barr virus: a clinicopathologic, cytogenetic study and literature review. Ann Diagn Pathol 2017;27:1-6.

14. Miyagi Maeshima A, Taniguchi H, Makita S, et al. Histopathological Characteristics of Lymphomas in the Upper Aerodigestive Tract. A Single-Institute Study in Japan. J Clin Exp Hematop 2015;55:7-11.

15. Galieni P, Cavo M, Pulsoni A, et al. Clinical outcome of extramedullary plasmacytoma. Haematologica 2000;85:47-51.

16. Niitsu N, Kohri M, Hayama M, et al. Primary pulmonary plasmacytoma involving bilateral lungs and marked hypergammaglobulinemia: differentiation from extranodal 
marginal zone B-cell lymphoma of mucosa-associated lymphoid tissue. Leuk Res 2005;29:1361-4.

17. Kim SH, Kim TH, Sohn JW, et al. Primary pulmonary plasmacytoma presenting as multiple lung nodules. Korean J Intern Med 2012;27:111-3.

18. Horiuchi T, Hirokawa M, Oyama Y, et al. Diffuse pulmonary infiltrates as a roentgenographic manifestation of primary pulmonary plasmacytoma. Am J Med 1998;105:72-4.

19. Mohammad Taheri Z, Mohammadi F, Karbasi M, et al. Primary pulmonary plasmacytoma with diffuse alveolar consolidation: a case report. Patholog Res Int 2010;2010:463465.

20. Ge X, Chen P, Zhang X, et al. Extramedullary plasmacytoma presented with multiple pulmonary plasmacytoma as first manifestation: a case report and literature review. Zhonghua Xue Ye Xue Za Zhi 2015;36:956-9.

21. Singhal S, Nath S, Karbowitz SR. Rapidly Progressive Primary Pulmonary Plasmacytoma. Chest 2010:138:123A.

22. Wen G, Wang W, Zhang Y, et al. Management of extramedullary plasmacytoma: Role of radiotherapy and prognostic factor analysis in 55 patients. Chin J Cancer Res 2017;29:438-46.

23. Soutar R, Lucraft H, Jackson G, et al. Guidelines on the diagnosis and management of solitary plasmacytoma of bone and solitary extramedullary plasmacytoma. $\mathrm{Br} \mathrm{J}$ Haematol 2004;124:717-26.

24. Tsang RW, Campbell BA, Goda JS, et al. Radiation Therapy for Solitary Plasmacytoma and Multiple Myeloma: Guidelines From the International Lymphoma Radiation Oncology Group. Int J Radiat Oncol Biol Phys 2018;101:794-808.

25. Thumallapally N, Meshref A, Mousa M, et al. Solitary

Cite this article as: Cheng $\mathrm{L}$, Guan $\mathrm{L}, \mathrm{Xu} \mathrm{Y}$, Liu Y, Zheng W, Yang T, Tan M, Zhu D, Gao X, Wang Q. Potential effect of epigenetic drugs in the treatment of multiple-site extramedullary plasmacytoma involving the respiratory system: a case report and review of the literature. Transl Cancer Res 2021;10(9):4262-4273. doi: 10.21037/tcr-21-68 plasmacytoma: population-based analysis of survival trends and effect of various treatment modalities in the USA. BMC Cancer 2017;17:13.

26. Español I, Martínez A, López MD, et al. First report of a medullar cord compression secondary to osseous plasmacytoma successfully treated with bortezomib and dexamethasone. Leuk Res 2010;34:e97-9.

27. Wei JY, Tong HY, Zhu WF, et al. Bortezomib in treatment of extramedullary plasmacytoma of the pancreas. Hepatobiliary Pancreat Dis Int 2009;8:329-31.

28. Zeng Z, Zheng L, Lin J, et al. Successful bortezomib treatment in combination with dexamethasone and thalidomide for previously untreated epidural plasmacytoma. Oncol Lett 2012;3:557-9.

29. Alzrigat M, Párraga AA, Jernberg-Wiklund H. Epigenetics in multiple myeloma: From mechanisms to therapy. Semin Cancer Biol 2018;51:101-15.

30. Dimopoulos K, Gimsing P, Grønbæk K. The role of epigenetics in the biology of multiple myeloma. Blood Cancer J 2014;4:e207.

31. McClure JJ, Li X, Chou CJ. Advances and Challenges of HDAC Inhibitors in Cancer Therapeutics. Adv Cancer Res 2018;138:183-211.

32. Ohguchi H, Hideshima T, Anderson KC. The biological significance of histone modifiers in multiple myeloma: clinical applications. Blood Cancer J 2018;8:83.

33. Pawlyn C, Kaiser MF, Heuck C, et al. The Spectrum and Clinical Impact of Epigenetic Modifier Mutations in Myeloma. Clin Cancer Res 2016;22:5783-94.

34. De Beck L, Melhaoui S, De Veirman K, et al. Epigenetic treatment of multiple myeloma mediates tumor intrinsic and extrinsic immunomodulatory effects. Oncoimmunology 2018;7:e1484981. 